\title{
Gastroesophageal reflux disease and the mother-infant relationship
}

\author{
Madalynn $\mathrm{Neu}{ }^{* 1}$, Beatrice Meyer-Parsons ${ }^{2}$, Erin Biringen ${ }^{3}$, Zeynep Biringen ${ }^{2}$ \\ ${ }^{1}$ College of Nursing, University of Colorado at Denver Anschutz Medical Campus, Denver, United States \\ ${ }^{2}$ Colorado State University, Fort Collins, United States \\ ${ }^{3}$ University of Colorado Boulder, Boulder, United States
}

Received: December 22, 2014

DOI: $10.5430 /$ jnep.v5n5p41
Accepted: February 12, $2015 \quad$ Online Published: March 8, 2015

URL: http://dx.doi.org/10.5430/jnep.v5n5p41

\begin{abstract}
The purpose of this study was to explore mother-child relational quality in infants diagnosed with Gastroesophageal Reflux Disease (GERD). Thirty-eight mothers and infants had been assessed during feeding using the Emotional Availability (EA) system at 6 to 10 weeks infant age. EA scores were in a non-optimal range. While this study is exploratory, given the small sample size and lack of a concurrent comparison group, this study on mother-child interactions and GERD suggests that further inquiry is warranted, both in research and in practice.
\end{abstract}

Key Words: Gastroesophageal reflux disease, Mother, Infant, Relationships

\section{INTRODUCTION}

Gastroesophageal reflux disease (GERD), a chronic digestive disorder involving the regurgitation of gastric contents into the esophagus, affects approximately $25 \%$ of infants during their first six months of life. ${ }^{[1]}$ In addition to frequent regurgitation, infants with GERD can be irritable and display sleeping and feeding difficulties, such as spitting, gagging, choking, and crying. ${ }^{[2]}$ Mothers of babies with GERD reported a lack of enjoyment in feeding, and they (mothers) were found to cry more frequently than a control group of mothers of healthy infants. ${ }^{[3]}$ Behaviors of infants with GERD and their mothers may threaten subsequent bonding and attachment. ${ }^{[4]}$ The purpose of this exploratory study was to assess mother-infant relationship quality for mothers and their babies with GERD.

The mother-child dyadic activity of feeding presents an ideal situation for interactional learning. Infants need to experience rewarding interactions with mothers in order to learn to regulate emotions, develop trust, and form an emotional bond with the parent. ${ }^{[5,6]}$ When the infant displays feeding difficulties, the mother may become anxious, leading to feelings of failure and fear of rejection by the infant. ${ }^{[7]}$ According to Farrow and Blisset ${ }^{[8]}$ infant feeding problems during the first six months of life may persist into early childhood. Mothers of these children reported more externalizing and internalizing problems than mothers of comparison groups. ${ }^{[9,10]}$

In an emotionally available mother-child relationship, members of the dyad share an emotional connection that is mutually fulfilling, and the responsiveness of the child and mother signifies that the relationship is important and valuable. ${ }^{[4,11]}$ Emotional availability, as measured by the Emotional Availability (EA) system has been shown to predict attachment. ${ }^{[12]}$ Others have reported lower EA (e.g. limited facial or verbal expression and lack of enjoyment in mothers, and lack of eye contact and/or smiling in infants) in the context of feeding problems. ${ }^{[13]}$

${ }^{*}$ Correspondence: Madalynn Neu; Email: madalynn.neu@ ucdenver.edu; Address: College of Nursing, University of Colorado at Denver Anschutz Medical Campus, Denver, United States. 
Most closest to the topic of this paper is the innovative study by Merras-Salmio and colleagues, ${ }^{[14]}$ who found that EA was lower in mother-baby dyads where the baby was suspected as having gastrointestinally manifested cow's milk allergy (that is, babies who appeared to show the types of qualities indicative of cow's milk allergy) as compared to a normative group with no suspected cow's milk allergy.

\section{MethodS}

\subsection{Sample}

Mothers $(n=38)$ of infants with GERD were contacted for an infant massage intervention study through pediatric care providers. Human Subjects approval was obtained and mothers signed informed consent. Infants were: a) born between 38 and 42 weeks gestational age; b) 5-12 weeks of age at enrollment; c) had a score of at least 16 on the Infant Gastroesophageal Reflux Questionnaire-Revised (IGRQR) and d) were diagnosed with GERD by their pediatric provider. Infants were healthy at birth and had no chronic illness other than GERD. Details of the intervention study are published. ${ }^{[15]}$

When enrolled into the intervention study, the mean score on the I-GERQ-R was 23.3 (SD = 4.0). Twenty-three infants $(60.5 \%)$ were boys and $16(42 \%)$ infants were breast fed during the assessments. Two mothers (5\%) were African American or Black, five (13\%) were Asian, seven (18\%) were Hispanic, three $(8 \%)$ were mixed race, and the remaining mothers $(56 \%)$ were white, non-Hispanic. Maternal age ranged from 21 to 39 years $(\mathrm{M}=31.1, \mathrm{SD}=4.1)$ at enrollment in the intervention study. Twenty-four mothers (63\%) completed 4-years of college or graduate studies. Because we assessed mother-child dyadic interaction at 6 to 10 weeks before any intervention, we combined scores of dyads from the treatment group and the control group in this investigation.

\subsection{Procedure}

When infants were 6 to 10 weeks of age, a pre-treatment feeding observation was videotaped in the infant's home. Mothers were instructed to feed the infant as usual. The research assistant was instructed to avoid initiating conversation with the mother during the feeding. Feeding observation videotapes were scored by observers using the EA system, a tool that has an established research base. ${ }^{[16-25]}$

\subsection{Measures}

\subsubsection{Gastroesophageal reflux questionnaire-revised}

Mothers completed the Infant Gastroesophageal Reflux Questionnaire-Revised (I-GERQ-R) ${ }^{[2]}$ to assess GERD in infants. The I-GERQ-R consists of 12 questions addressing the symptom cluster for GERD identified in the literature. Questions address amount and discomfort attributed to regurgitation ( 3 items), crying and fussing (3 items), arching back (1 item), refusal or stopped feeding ( 2 items), hiccups (1 item), and apnea or color change ( 2 items). ${ }^{[2]}$ The score ranges from 0 to 42 . Validation of the I-GERQ-R was conducted in seven countries. Results of studies of 185 infants with diagnosed GERD and 93 control infants showed internal consistency reliability of $0.86-0.87$ and test-retest reliability of 0.85 . A cut-off score of 16 yielded sensitivity of .65 and specificity of 1.0. Pediatricians diagnosed $50 \%$ of infants based on parent report and the remaining $50 \%$ with pHmetry or endoscopy. Scores on the I-GERQ-R were similar in infants with GERD regardless of diagnostic method. Construct validity was shown by significant differences between GERD and control groups on individual items; total score; correlation with a parent daily diary of spitting, crying, arching back, and stopped eating; and correlation with physician and caregiver ratings of disease severity. Mean baseline to 3-week change scores differed significantly between infants reported improved versus those reported as showing no change. The I-GERQ-R can be used to validly diagnose infant GERD and monitor treatment outcomes. ${ }^{[2]}$

\subsubsection{Emotional Availability system}

The Emotional Availability system consists of the Emotional Availability (EA) scales ${ }^{[16,17]}$ and the Emotional Attachment and Emotional Availability Clinical Screener (EA2-CS). The EA Scales were used to score feeding observations when the infant was 6 to 10 weeks of age. The availability of emotional communication that includes range of emotions and the quality of positive and adaptive emotions are considered an essential aspect of the relationship and of parental nurturing and guidance. ${ }^{[18]}$ The EA Scales have been used in more than 100 studies $^{[19]}$ with every age group including infants during the first year of life. Biringen and Easterbrooks ${ }^{[4]}$ describe four adult components of emotional availability: Sensitivity (appropriate responsiveness and ability to handle conflicts in the relationship); Structuring (consistent, nonexcessive limit setting and guidance during the child's play); Nonintrusivness (age appropriate protectiveness of the child without overdirection or overstimulation); and Non-hostility (absence of impatient, angry, or bored facial or verbal behavior). The two child components are: Responsiveness (willingness to respond to bids of the adult without over-compliance), and Involvement (ability to initiate an interaction and engage the adult without over-involvement or distress). Scores for each subscale range from 1 to 7 , higher scores indicating more optimal emotional availability. ${ }^{[16]}$

Moderate short-term stability in individual EA infant characteristics was demonstrated in infancy and toddlerhood. ${ }^{[23]}$ 
Maternal display of right frontal activation to their 5 to 8 month-old infants' expressions of emotions (joy, anger, and distress) was associated with maternal EA sensitivity, structuring, and non-intrusiveness -.38 to $-.47, p<.05,{ }^{[24]}$ indicating an emotional response and concurrent validity. In children 3 weeks through 3.5 years, EA scores discriminated between feeding, regulation (sleeping and crying), externalizing disorders, and attachment $(p<.05)$ with lowest scores for feeding and regulation. ${ }^{[25]}$

In addition to the 6 EA dimensions described above, the EA system now also includes the Emotional Attachment and Emotional Availability Clinical Screener ${ }^{[16]}$ (EA2-CS), which is rated on a 100-point dimensional scale, that is divided into four zones that correspond conceptually to attachment categories. The four zones include Emotionally Available (81-100), Complicated Emotional Availability (61-70), Emotionally Unavailable/Detached (41-60), and Problematic/Disturbed (1-40). Studies have indicated a significant link between the EA2-CS and the 0-3 Diagnostic Classification Parent-Infant Relationship Global Assessment Scale (DC 0-3 PIRGAS), ${ }^{[20]}$ to an infants' ability to interpret human actions as goal-directed, ${ }^{[21]}$ and attachment. ${ }^{[22]}$

Given that the current data set involved the youngest age group for the use of this system, and breastfeeding interactions occur in a constrained context, the EA Scales were double scored by trained coders who had achieved reliability (intraclass correlations $>.80$ ) with other data sets. When disagreement greater than 2 points occurred, the coders (second author and research assistant)) discussed the observation until agreement was reached, on occasion consulting with the developer of the system. The conferenced score was used in analyses.

\subsection{Case study example of a commonly observed inter- action between a mother and her baby with GERD}

Mom situates herself on the bed (putting some pillows to support her back), and places her baby on her breast. She smiles and seems engaged with the start of breastfeeding. She seems relieved that her baby is sucking and sits back, looking at her baby. Her face looks tired, distracted, even preoccupied. She takes out her phone, and begins to text. As she continues her text, mom seems to become absorbed in the activity. Baby groans and moves about, as if objecting to the lack of attention, hugging, encouraging. But, in response to baby's initiations, mom situates herself in a better position to be able to continue her texting. Baby begins to move some more, but mother seems not to attend to these cues. Mom continues to appear tired but does smile occasionally. She strokes the baby's head and back occasionally and baby Published by Sciedu Press calms.

\section{RESULTS}

While norms are not available for the EA system, the EA2$\mathrm{CS}$ is an attachment-relevant score and provides an overall global measure of the relationship. The mean score on the EA2-CS suggests a Complicated relationship per the EA coding system, where the mother and infant are not judged to be affectively healthy. For the most part, the means for the six EA Scales also indicate the scores are in the midrange, and hence, without clear emotional availability in the mother-infant relationship. While there were clear examples of emotionally connected, engaged, and affectively positive breastfeeding interactions in this group, many more relationships appeared without clear engagement and enjoyment, as below (see Table 1).

Table 1. Means and standard deviations for the EA scales and EA2 clinical screener

\begin{tabular}{lll}
\hline EA & Mean & Standard deviation \\
\hline Maternal Sensitivity & 5.04 & 1.09 \\
Maternal Structuring & 5.04 & .78 \\
Maternal Nonintrusiveness & 5.84 & .99 \\
Maternal Nonhostility & 5.57 & .91 \\
Child Responsiveness to the Adult & 4.38 & .82 \\
Child Involvement of the Adult & 4.03 & .95 \\
Emotional Attachment \& & & \\
Emotional Availability (EA2) & 70.23 & 15.33 \\
Clinical Screener & & \\
\hline
\end{tabular}

\section{Discussion}

In the language of the very global EA system, the highly Sensitive mother exhibits genuine interest and enjoyment interacting with the infant. Her behavior is flexible and congruent with the needs signaling behavior of the infant. Optimal Structuring comprises a framework for infant interactional behavior that is relaxed but moves the child in the desired direction. Optimal Non-hostility is total lack of facial or vocal negativity (e.g., hostile tone of voice, ridiculing, expressions of anger, frowning, or hitting). Non-intrusiveness indicates maternal emotional presence without being too directive, stimulating, or protective. ${ }^{[16]}$ Behaviors of a more emotionally available mother when the infant with GERD is experiencing discomfort during feedings could form a pattern of feelings of trust and confidence. Returning the serve, the infants of emotionally available mothers would be emotionally Responsive during feeding and Involve and engage the caregiver appropriately.

In an earlier analysis of this data set using the Nursing Child 
Assessment Feeding Scale (NCAFS), ${ }^{[26]}$ scores in this sample of mothers and their infants with GERD were lower than a national sample. ${ }^{[27]}$ The NCAFS is a more discrete observational tool that specifically addresses mother-infant interaction during feeding. EA and NCAFS scales represent somewhat different maternal-infant behaviors, but these dyads scored less than optimally on both. Subscales on the NCAFS are a mother's Sensitivity (e.g., recognizes infant feeding cues and terminates feeding when infant shows satiation); Responsiveness to distress during feeding (e.g., recognizes infant distress and interrupts feeding to soothe the infant); Social-emotional growth fostering (e.g., mother does not behave in an antagonistic manner toward the infant, and so avoids behaviors such as hitting or shaking, negative comments, facial expressions such as grimacing and frowning), and Cognitive Growth Fostering (maternal verbalizations in response to infant feeding behavior or infant exploration of feeding objects). Infant subscales are responsiveness to the mother's verbal and nonverbal signals, and clarity of infant feeding cues. ${ }^{[26]} \mathrm{Neu}$ and colleagues ${ }^{[27]}$ reported that maternal scores indicated that they did not communicate with their infants verbally, engage in eye contact, or smile at their infants at the same level as the normative sample. The infants did not display clear feeding cues or respond to attempts by their mothers to interact at the same level as the national sample $(p<.001)$. Cognitive and social-emotional growth fostering may be easier and more abundant when a child does not experience feeding difficulties such as GERD. In return, the infant may be more responsive and show clarity of cues during the feeding.

The less than optimal EA scores found by Merras-Salmio et $a l .{ }^{[14]}$ in a sample of mothers and their infants with suspected cow's milk allergy are similar to findings of this current study. Infants with GERD or other gastrointestinal problems who are experiencing discomfort that is not alleviated while being held and fed by the mother would potentially have difficulty developing trust in the mother that would impact the mother-child relationship. Infants and children desire close proximity to the mother when threatened by a challenge, and while many mothers are able to provide such comfort, for others, it may mean a less optimal start to the mother-child relationship. ${ }^{[4]}$ It is possible that the persistent feeding difficulties and internalizing and externalizing disorders reported in children who had feeding problems in the first months of life ${ }^{[8-10]}$ are associated with a less than optimal early motherinfant relationship. This is an area for future research.

This study suggests that future research and clinical work might consider further examination of the mother-child relationship when an infant presents with GERD. Given that $25 \%$ of the general population of infants experience this problem, GERD may present a challenge to the development of an optimal mother-child relationship. While the problem most often resolves by the end of the first year of life, this period is also a sensitive time for establishing a positive trajectory and security in the mother-child bond. This is the first study to explore the link between mother-child emotional availability and the context of GERD.

\section{CONFlicts OF INTEREST Disclosure}

Author Zeynep Biringen has identified a potential conflict of interest, given the use of the EA system. Other authors report no conflict of interest.

\section{REFERENCES}

[1] Nelson SP, Chen EH, Syniar GM, et al. Prevalence of symptoms of gastroesophageal reflux during infancy. A pediatric practice-based survey. Pediatric Practice Research Group. Arch Pediatr Adolesc Med. 1997 Jun; 151(6): 569-72. PMid:9193240 http://dx.doi.o rg/10.1001/archpedi.1997.02170430035007

[2] Kleinman L, Rothman M, Strauss R, et al. The infant gastroesophageal reflux questionnaire revised: development and validation as an evaluative instrument. Clin Gastroenterol Hepatol. 2006 May; 4(5): 588-96. PMid:16678075 http://dx.doi.org/10.1016/j . cgh.2006.02.016

[3] Mathisen B, Worrall L, Masel J, et al. Feeding problems in infants with gastro-oesophageal reflux disease: a controlled study. J Paediatr Child Health. 1999 Apr; 35(2): 163-9. PMid:10365354 http://dx .doi.org/10.1046/j.1440-1754.1999.t01-1-00334.x

[4] Biringen Z, Easterbrooks MA. 2012 Emotional availability: concept, research, and window on developmetnal psychopathology. Dev Psychopathol. 2012 Feb; 24(1): 137-42. PMid:22396974 http: //dx.doi.org/10.1017/S0954579411000733
[5] Black MM, Aboud FE. Responsive feeding is embedded in a theoretical framework of responsive parenting. J Nutr. 2011 Mar; 141(3): 490-4. PMid:21270366 http://dx.doi.org/10.3945/jn.110. 129973

[6] Kochanska G, Woodard J, Kim S, et al. Positive socialization mechanisms in secure and insecure parent-child dyads: two longitudinal studies. J Child Psychol Psychiatry. 2010 Sep; 5(9): 9981009. PMid:20406336 http://dx.doi .org/10.1111/j.1469-7 610.2010.02238. $\mathrm{x}$

[7] Karacetin G, Demir T, Erkan T, et al. Maternal psychopathology and psychomotor development of children with GERD. Pediatr Gastroenterol Hepatol Nutr. 2011 Oct; 53(4): 380-5.

[8] Farrow C, Blisssett J. Maternal cognitions, psychopathologic symptoms, and symptoms and infant temperament as predictors of early infant feeding problems: a longitudinal study. Int J Eat Disord. 2006 Mar; 39(2): 128-34. PMid:16231348 http://dx. doi .org/10.10 02/eat. 20220

[9] McDermott BM, Mamun AA, Najmn JM, et al. Longitudinal correlates of the persistence of irregular eating from age 5 to 14 years. 
Acta Paediatr. 2010 Jan; 99(1): 68-71. PMid:19811457

[10] Ostberg M, Hagelin E. Feeding and sleeping problems in infancy a follow-up at early school age. Child Care Health Dev. 2010 Jan; 37(1): 11-25. PMid:20666781 http://dx.doi.org/10.1111/j $.1365-2214.2010 .01141 . x$

[11] Aviezer O, Sagi A, Joels T, et al. Emotional availability and attachment representation in kibbutz infants and their mothers. Dev Psychol. 1999 May; 35(3): 811-21. PMid:10380871 http://dx .doi.org/1 $0.1037 / 0012-1649.35 .3 .811$

[12] Ziv Y, Aviezer O, Gini M, et al. Emotional availability in the motherinfant dyad as related to the quality of infant-mother attachment relationship. Attach Hum Dev. 2010 Sep; 2(2): 149-169. PMid:11707908 http://dx.doi.org/10.1080/14616730050085536

[13] Gueron, Sela N, Atzaba-Poria N, et al. Maternal worries about child underweight mediate and moderate the relationship between child feeding disorders and mother-child feeding interactions. J Pediatr Psychol. 2011 Aug; 36(7): 827-36.

[14] Merras-Salmio L, Salo S, Pelkonen AS, et al. How mothers interact with children with suspected cow's milk allergy symptoms. Acta Paediatri. 2013 Dec; 102(12): 1180-5. PMid:24033685 http: //dx.doi.org/10.1111/apa.12408

[15] Neu M, Pan Z, Workman R, et al. Benefits of massage therapy for infants with symptoms of gastroesophageal reflux disease. Biol Res Nurs. 2014 Oct; 16(4): 387-97. PMid:24379449 http: //dx.doi .o rg/10.1177/1099800413516187

[16] Biringen Z. The Emotional Availability (EA) Scales, 4th Ed. 2008. Boulder, CO: Emotionalavailability.com.

[17] Biringen Z, Robinson J, Emde R. The Emotional Availability (EA) Scales (2ND and 3rd editions, 1998), Boulder, CO.

[18] Emde RN. Emotional availability: critical questions and research horizons. Dev Psychopathol. 2012 Feb; 24(1): 125-9. PMid:22292999 http://dx.doi.org/10.1017/S095457941100071X

[19] Beeghly M. A developmental psychopathology perspecitve on emotionals availability research: current treands and challenges. Dev
Psychopathol. 2012 Feb; 24(1): 107-11. PMid:22292997 http: //dx.doi.org/10.1017/S0954579411000691

[20] Espinet SD, Jeong JJ, Motz M, et al. Multimodal assessment of the mother-child relationship in a substance-exposed sample: Divergent associations with the Emotional Availability Scales. Inf Mental Hlth J. 2013 Nov/Dec; 34(6): 496-507. http://dx.doi.org/10.1002 /imhj. 21409

[21] Licata M, Paulus M, Thoermer C, et al. Mother-infant interaction quality and infants' ability to encode actions as goal-directed. Soc Devel. 2014 May; 23(2). http://dx.doi.org/10.1111/sode. 12057

[22] Baker MA, Biringen Z. Emotional Attachment \& Emotional Availability Clinical Screener (EA2-CS): A Dyadic assessment in the context of center-based child care. Poster presented at the 27th National Training Institute Conference; 2012 December; Los Angeles, CA.

[23] Bornstein M, Gini M, Putnick D, et al. Short-term reliability and continuity of emotional availability in mother-child dyads across contexts of observation. Infancy. 2006 July; 10(1): 1-16. http: //dx.doi.org/10.1207/s15327078in1001_1

[24] Killeen LA, Teti DM. Mothers' frontal EEG asymmetry in response to infant emotion states and mother-infant emotional availability, emotional experience, and internalizing symptoms. Dev Psychopathol. 2012 Feb; 1(1): 9-24. PMid:22292990 http://dx.doi.org/10. $1017 /$ S0954579411000629

[25] Wiefel A, Wollenweber S, Oepen G, et al. Emotional availability in infant psychiatry. Inf Mental Hlth J. $2005 \mathrm{Jul} ; 26(4)$ : 392-403. http://dx.doi.org/10.1002/imhj.20059

[26] Sumner G, Spietz A. Caregiver/parent-child interaction feeding manual. Seattle, WA: NCAST Publications; 1996.

[27] Neu M, Schmiege SJ, Pan Z, et al. Interaction during feeding with mothers and their infants with symptoms of gastroesophageal reflux. J Altern Complement Med. 2014 Jun; 20(6): 493-9. PMid:24742255 http://dx.doi.org/10.1089/acm.2013.0223 